\title{
1. Social trust: its concepts, determinants, roles, and raising ways
}

\subsection{INTRODUCTION}

As Aristotle observed 2400 years ago, human beings are by nature social creatures. Social trust is the underlying foundation of relationships among individuals, groups, and other components of a society. Knack and Zak (2003) claim that 'trust is essential to myriad aspects of civil society'. People exercise a certain extent of trust when dealing with others, and on this basis expect certain types of responses. Without trust in others' actions, people may have to consider too many contingencies and uncertainties to take action, destroying the foundation of community and society. Without social trust, a country's economy cannot perform well, because transaction costs - costs in undertaking economic transactions by economic entities would be too high. Hence, social trust is a key determinant of social and economic development as well as of human well-being.

Social trust has been a serious social and economic issue in Korea in the recent past. It has been found to be remarkably low in Korea relative to living standards in Korea and to levels of social trust in other countries. On 'interpersonal trust', a constituent element of social trust measured by the World Values Survey (WVS), Korea ranked 31st with a score of 31.7 over the period 1981-2008 (Algan and Cahuc 2013). This indicates only 31.7 percent of Koreans responded 'most people can be trusted'. The Korean score compares to Norway's score of 68.1, which ranked highest over the same period. Even more serious is that social trust has declined over the past four decades. Korea's score of 36.0 by Wave 1 (1981-84) of the WVS declined to 26.5 by Wave 6 (2010-14), which is the latest WVS survey. ${ }^{1}$ Taking into account that different numbers of countries were surveyed over the six waves, Korea ranked in the 38th percentile on average over the six waves. According to the Wave 6 Survey, Asian neighbours including Japan, China, Hong Kong, Taiwan, and Singapore scored higher levels of interpersonal trust than Korea, let alone northern European countries.

Prospects for interpersonal trust in Korea are not bright. A 2014 survey of middle and high school students found that only 12.4 percent said they feel most people can be trusted (The Dong A Ilbo 2014). As discussed 
further in Chapters 7, 8, and 9, institutional trust, another component of social trust, is also low in Korea, by comparison with neighbouring Asian and northern European countries. As Tabellini (2008) has suggested, the maintenance of low institutional and interpersonal trust over an extended period develops a social culture of distrust, which by nature transmits across many generations.

Understanding that low social trust in Korean society has potentially serious consequences for its economy and society, this chapter discusses concepts, types, determinants, and measurements of social trust. It then analyses how social trust affects economic and social development. It does not attempt an extensive survey of the vast literature on social trust, nor does it delve into the complexities of the concept of social trust, both of which are beyond the scope of this book's focus on the Korean economy and society. Rather, the main purpose of this chapter is to develop a working definition of social trust and a conceptual framework for examination and discussion throughout this book. These provide the basis for drawing some public policy proposals on how to raise social trust in a national context.

Social trust as a concept is multidimensional. A large number of researchers, emphasizing particular aspects, have defined it in a variety of ways (Morrone et al. 2009). For this study, the concept of social trust extends beyond 'interpersonal trust', which refers to trust among individuals. Society is comprised of more than individuals; it has its own structure, institutions, and organizations. Thus, within society there is individuals' trust not only in each other (interpersonal trust), but also in institutions and organizations (such as government, police, business, and labour unions). The latter is referred to as institutional trust (Putnam 2000; Morrone et al. 2009).

The two constituent components of social trust certainly influence each other in a society. ${ }^{2}$ This book investigates separately the social trust among individuals and their trust in institutions, for consistency with this study's institutional approach that stresses institutional effects on social trust and economic development. Interpersonal trust in Korea is discussed in Chapter 6. Three specific types of institutional trust in Korea have been selected for this study - trust in government, business, and labour - and these are investigated, respectively, in Chapters 7, 8, and 9. Institutional trust is particularly important when social trust is compared across countries. This is because cross-country differences in social trust arise largely from institutional trust, as institutions and their implementation are quite different across countries. Hence, this book explores the differences in social trust between Korea and its neighbouring countries in analysing the effects of social trust on economic development (Chapter 4). 


\subsection{SOCIAL TRUST VERSUS SOCIAL CAPITAL}

This study focuses on social trust - not on social capital. Social capital is generally defined as a type of resource embedded in relationships among individuals that facilitates cooperative and collaborative actions within society (Coleman 1988; Putnam 1993). As Arrow (1999) identified, the term 'capital', as in physical and human capital, has a connotation of deliberate sacrifice in the present for benefit in the future. In general, however, people pursue social relationships, not for future benefits at the expense of present ones, but for the intrinsic value of these social relationships. From the literature, it appears that studies have failed to note that while physical and human capital are allocated through the price mechanism in the market, there is no mechanism that allocates social capital. Without an allocation mechanism, social capital as a resource faces operational issues. These differences mentioned briefly here make clear that the argument for equivalence of social capital with physical and human capital is tenuous at best.

Although there is controversy over the specific components of the relationships that generate social capital, these components include social trust, social networks, and memberships of voluntary associations (Coleman 1988; Putnam 1993). All the components of social capital are expected to bring benefits to society, yet social trust appears to be the most important component of social capital (Fukuyama 1995; Paldam and Svendsen 2000; Newton 2013). Furthermore, benefits of social networks and their memberships are less clear, particularly when social capital is compared across countries. The meaning of social networks can differ by country. In group (or collectivist) societies such as Korea, a large number of social networks or voluntary associations have high limited (or in-group) trust among their members. Limited trust has negative effects on interpersonal trust among strangers. When group members satisfy their needs for interpersonal interactions among in-group members, they have limited motivation and experience to deal with people outside their group (Ermisch and Gambetta 2010; Algan and Cahuc 2013; Delhey and Newton 2003). Hence, increases in limited trust through membership in social networks may not facilitate cooperation and collaboration within society, since it lowers generalized trust.

As a practical matter, a number of worldwide organizations have measured social trust across countries in a consistent manner over time. This book makes use of data obtained in that research. However, few organizations measure social capital as such, so there is a paucity of available data on social capital across countries. Samsung Economic Research Institute (SERI) estimated the levels of social capital of 72 countries in 2008 (Lee 
and Jeong 2009), with the components of social capital including social trust, norms, networks, and social structure. However, SERI's 2008 estimates excluded Singapore and Hong Kong, and SERI has not estimated social capital since its first estimation. This diminishes the utility of SERI data for the present study.

\subsection{INTERPERSONAL TRUST: CONCEPT AND DETERMINANTS}

\subsubsection{The Concept of Interpersonal Trust}

Extending the definition of Coleman (1990), in this study interpersonal trust is defined as individuals' expectations of other members of society to act and behave in a way that is beneficial to these individuals or at least not detrimental to them. Interpersonal trust reflects people's subjective perspective of others' reliability without legal commitment, and involves a degree of risk and uncertainty. Hence, trust involves two components: expectations and willingness to take risky actions based on the expectations.

There are two types of interpersonal trust: trust in family members, friends and members of groups or associations, and trust in strangers. The former is referred to as limited (or in-group or thick) trust, and the latter to generalized trust (Algan and Cahuc 2013). In-group members develop norms and values for the group members to follow as acceptable behavioural guidelines. Members who violate in-group norms may be sanctioned or ostracized by the group. Hence, behavioural conformity among group members is high, and interpersonal trust among them is strong or thick.

Generalized trust among strangers, however, is the concept of interpersonal trust commonly used in the literature. It is often measured by worldwide organizations such as the WVS, the European Social Survey, and the General Social Survey. These organizations survey the perceptions of interpersonal trust held by individuals, using the well-known trust survey question, 'Generally speaking, would you say that most people can be trusted, or that you can't be too careful when dealing with others?' The two answers offered for respondents to choose from are: 'Most people can be trusted' or 'Need to be very careful'. The proportion of survey respondents who choose the former answer is regarded as indicating the level of interpersonal trust of a country. However, an intrinsic limitation of the survey should be noted here: in seeking to measure generalized trust using these questions, the survey makes no serious attempt to define 'trust' itself, since using 'trust' to define the term 'trust' is clearly tautologous. 
As mentioned above, it is quite likely that limited trust and generalized trust are negatively related. People with strong group identities with limited in-group trust do not feel the necessity, nor have much experience of interacting with outsiders. Groups may also increase dissension and competition among them, thereby creating conflicts among them and lowering generalized trust (Knack and Keefer 1997; Ermisch and Gambetta 2010). A recent study cited by Reader's Digest (2015) shows that more time spent with acquaintances may lead us to be less empathetic toward others. The present study focuses on the latter and refers to it as interpersonal trust, unless otherwise indicated.

\subsubsection{Determinants of Interpersonal Trust}

\section{The individual-oriented theory of interpersonal trust}

The level of social trust in a country, including both interpersonal and institutional trust, is built up over time by a number of factors. Figure 1.1 provides a graphical overview of social trust, its types, and its determinants, as examined in this chapter. With regard to interpersonal trust, there are two broad schools of thought on the determinants (Delhey and Newton 2003; Newton 2013; Algan and Cahuc 2013). The first one, referred to as the individual-oriented theory, takes the view that interpersonal trust is an individual property associated with individual characteristics including individuals' personality traits (including morality) and their social and demographic features such as age, social status, gender, education, income, and religion. The second school of thought, referred to as the society-based theory, views that interpersonal trust is not a property of individuals but a systematic and emergent property of society. As examined below in detail, the society-based theory argues that interpersonal trust is determined not by individual characteristics,

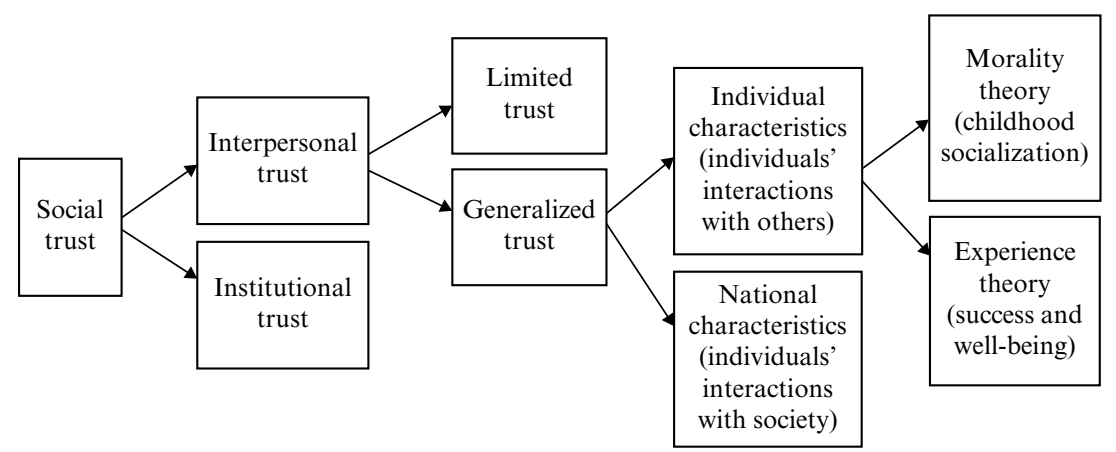

Figure 1.1 Types and determinants of social trust 
but by social and national characteristics such as history, culture, economy, institutions, geography, and public policy.

(i) Interpersonal trust as a moral value The individual-oriented theory of interpersonal trust suggests two routes through which interpersonal trust develops (Uslaner 2008; Newton 2013). One regards interpersonal trust as a moral value that people learn early in their lives largely from their parents. People also develop moralistic trust from undertaking or observing good deeds such as charitable giving and volunteering. A long tradition of psychology argues that people learn a basic propensity to trust during their childhood and formative years. In this regard, Katz and Rotter (1969) showed that 75 percent of the variation in teenagers' trust levels could be explained by their parents' propensity to trust most other people. Morality-based trust, which develops from people's childhood, reflects their personality characteristics including optimism, honesty, cooperation, reciprocation, respect, and benevolence (Larzelere and Huston 1980; Fukuyama 1995). Interpersonal trust based on personality characteristics is stable throughout people's lives, because personality does not change easily (Uslaner 2008; DeSteno and Valdesolo 2011). If people share such personality characteristics as norms, interpersonal trust should be higher among them. It follows that interpersonal trust is likely to be high among people with the same ethnic background who typically share the same norms (Delhey and Newton 2003). This in turn suggests that the level of interpersonal trust is likely to differ between ethnic groups within a country, and thus the higher the level of ethnic homogeneity within a country, the higher that country's level of interpersonal trust.

(ii) Interpersonal trust from experiences of interacting with others The other route argues that people develop interpersonal trust not from early childhood socialization but from their adult life experiences through their interactions with others. People with positive experiences with others, such as being treated well, increase their sense of trust in others. Experience-based interpersonal trust would have some special features. It would be fragile, as people modify and update their feelings of trust in response to their personal experiences. People who are well treated are in general 'winners' in a society. Hence, those who are successful, wealthier, and better educated, and those who have a high social, political, and economic status, have a higher tendency to trust others because others have treated them well. As mentioned earlier, trust involves a degree of risk, and wealthier people can afford to risk more than the poor, thereby they can trust more (Offe 1999). Successful people are in general more 
optimistic, satisfied, and happier in life, and by extension better treated by others, so they have a high predisposition to trust others (Warren 1999). In comparison, people who are 'losers' in a society have a low tendency to trust others. These people include those suffering from poverty, discrimination, exploitation, unemployment, social exclusion, and victims of fraud and swindles (Newton 2013). Through the process of interpersonal experiences, a virtuous (or vicious) circle will develop that will mutually reinforce trusting (or distrusting) behaviour. Winners in society treat well and trust others, who, in turn, reciprocate with respect and better treatment, while losers, being treated poorly, treat others accordingly.

\section{The society-based theory of interpersonal trust}

The society-based theory argues that people develop trusting attitudes and behaviour from participation in society (Putnam 1993). In this theory, key determinants of interpersonal trust include social and national characteristics or circumstances such as history, culture, living standards, equity, institutions, ethnic composition, and geography. ${ }^{3}$ We can easily observe that personal characteristics at the individual level (e.g., honesty, cooperation, reciprocity, and respect) of a number of advanced and emerging countries are quite similar. Yet their generalized trust levels are quite different. This implies that country-fixed characteristics would be critical reasons for the differences in trust levels across countries. ${ }^{4}$

(i) History If a nation's people have experienced a historical period of conflict and tumult, we can expect that the nation's level of interpersonal trust in the wake of such experience will be low (Newton 2013). This is true, for example, for the people of Germany through much of the first half of the 20th century including WWI and WWII, and for the people of Korea through colonization by Japan (1910-45) followed soon by the Korean War (1950-53). Once trust is lost in a society for any reason, it is difficult to regain because the lack of trust - or indeed, active distrust - is ingrained in people's mindsets and is thus embedded in their culture, which by its very nature does not change easily. ${ }^{5}$

(ii) Living standards, equality, and fairness in society Economic development contributes to interpersonal trust through improvements in economic security and economic well-being of citizens, which, in turn, reduce the perceived risks that diminish trust. A number of empirical studies support the positive relationship between economic growth and interpersonal trust (Knack and Keefer 1997; Knack and Zak 2003; Algan and Cahuc 2013). Countries worldwide have witnessed during periods of economic 
recession the emergence of rent-seeking interest groups, which render public policy inefficient and increase social conflicts. In a country with high inequality in terms of income, social status, or power, it is difficult to establish bonds between those at the top and those at the bottom. Indeed, inequality increases conflicts and jealousy, and lowers interpersonal trust. Delhey and Newton (2003) found that the social condition of conflict is one of the most important determinants of the level of interpersonal trust. Of the many types of inequality, income inequality appears to be one of the most significant variables associated with low interpersonal trust (Rothstein and Uslaner 2005; Bjornskov 2007). As exploration in Chapter 6 reveals, interpersonal trust has a circular relationship with perceptions of injustice; perceived injustice leads to distrust, which, in turn, promotes future perceptions of injustice (DeConick 2010).

(iii) National culture This has significant influence on interpersonal trust through many channels (Doney et al. 1998). Putnam (1993) argued that differences in trust between people in North Italy and in South Italy were attributable to culture and history. As mentioned earlier, collectivism, for instance, leads to low interpersonal trust as compared to individualism. In addition, many types of groups or associations in societies with high limited interpersonal trust compete and check each other for their own benefit or even survival, lowering interpersonal trust. Culture also affects interpersonal trust as it underlies ethics, honesty, cooperation, reciprocity, respect, and benevolence. One of the two main components of interpersonal trust is the willingness to take risk. It is well understood in the management literature that the willingness to take risk is rooted in culture. In this regard, Hofstede (1991) measured avoidance of uncertainty (risk aversion) - the degree to which societies are willing to accept and deal with uncertainty - across countries as a dimension of national culture. As Hofstede found, differences in uncertainty avoidance lead to differences in interpersonal trust across countries.

Religion, which underlies culture, has bearings on interpersonal trust. Hierarchical religions such as Catholicism, Islam, and Confucianism tend historically to foster lower interpersonal trust among adherents than Protestantism (Zak and Knack 2001; Delhey and Newton 2005). Religiosity itself, like collectivism, is found to have a negative effect on interpersonal trust, because religious groups trust primarily people in their own groups, while distrusting others. This causes divisions and conflicts in the broad population (Berggren and Bjornskov 2009).

(iv) Formal institutions (the legal and governance systems) Quality and implementation of formal institutions play an important role for inter- 
personal trust within society (Zak and Knack 2001). Democratic nations are found to have higher levels of interpersonal trust than authoritarian regimes, because in democratic nations citizens have freer association and participation in social and political activities, less oppressive regulatory measures, better protection of private property rights, and smaller gaps in political power. Legal institutions (rules and regulations) play a central role in breeding interpersonal trust (Alesina and La Ferrara 2002; Rothstein and Stolle 2008). As explored in Chapter 6, firm observance of the rule of law leads to development of trusting attitudes and behaviour, as people feel protected against improper conduct and are satisfied with public safety (Delhey and Newton 2003). To this end, Rothstein and Stolle (2008) argued that legal institutions should be impartial, fair, and efficient. Interpersonal trust and implementation of legal institutions develop a circular relationship. If people perceive that others do not comply with formal rules, it raises their perception of injustice and lowers their trust toward fellow citizens (DeConick 2010; Algan and Cahuc 2013). Observance of rules and regulations rests on cultural roots and differs by country (Fukuyama 1995: 25). To this extent, a nation's culture and formal institutions reinforce each other with regard to trust.

(v) Moral hazard Perhaps surprisingly, moral hazard has not been identified in the literature as a source of social distrust (both interpersonal and institutional distrust). Moral hazard occurs when a person takes more risks because they understand someone else bears the burden of those risks if the risk-taking fails. Hence, those who engage in moral hazard will take more risks than otherwise to the detriment of others or society. There have been numerous cases of moral hazard in the recent past. For example, the originators of subprime loans in the US sold the loans beyond an extent that buyers and society saw to be appropriate, due to information asymmetry. Financial bailouts of lending institutions (including the originators of subprime loans) by the US government encouraged risky lending and increased potential moral hazards. In this instance, moral hazard arose from a principal-agent problem. Chaebols, Korean business conglomerates, had undertaken risky economic activities (e.g., expanding their business empires with debt capital) under an illusion that they were 'too important to fail', and so would be bailed out by the government if financial trouble threatened their operating capacity. This was one of the main sources of the 1997 financial crisis in Korea. Moral hazard is not illegal, and as long as business operations do not go badly, moral hazard activities will not be discovered. Once bad business operations are revealed, however, citizens regard them as unfair and not consistent with social justice, thereby reducing interpersonal trust. Also, citizens then 
consider that moral hazard activities could be pursued because of poverty of the legal system, which lowers citizens' trust in institutions.

(vi) Geography Geography has a bearing on interpersonal trust, as weather and terrain develop the type of society that people form. Le (2013) shows that higher geographical latitude leads to lower disease prevalence, lower income inequality, and less ethnic and linguistic heterogeneity, and these in turn lead to higher social trust. He also points out that more rugged terrain leads to low social trust, probably because in this terrain small-sized groups usually develop and they do not communicate much among the groups.

(vii) Ethnic composition The ethnic composition of society also has bearings on interpersonal trust. DeBruine (2002) argues that one factor that enhances interpersonal trust is facial resemblance. People with the same ethnic background and facial resemblance have similar cultural backgrounds including norms and values. This leads to racial affinity and high trust among them. However, ethnic-oriented groups can foster greater racial tension among ethnic groups, and damage overall interpersonal trust such as groups in a collectivist society. In America, mutual distrust is often the norm in race relations (Warren 1999: 18).

\subsection{INSTITUTIONAL TRUST: CONCEPT AND DETERMINANTS}

\subsubsection{The Concept of Institutional Trust}

Institutional trust is the confidence of citizens in institutions. Citizens expect institutions to perform efficiently, effectively, fairly, and ethically in accordance with the roles assigned to them by law or with social norms in the eyes of citizens (Newton 2006; Kelleher and Wolak 2007; Warren 1999). People's trust in institutions is not the same kind of trust as that between each other as individuals. Interpersonal trust is based on immediate, first-hand experience of other individuals, whereas institutional trust is more generally learned indirectly and at a distance, usually through the media and social intercourse (Newton 2013). Interpersonal trust is an expression of the basic features of trusting personalities, whereas institutional trust is based on an evaluation of the performance of institutional functions. Evaluation can be made of the institutions or of the personnel in charge of the institutions. For instance, confidence in government can originate from popular perception of politicians and bureaucrats who 
fulfil their duties in a trustworthy manner. Interpersonal trust is regarded as positive since it contributes to civilization and cooperation within society. Institutional trust is also regarded as positive in the sense that it improves the functioning of institutions and improves the trustworthiness of personnel in charge, also enabling them to fulfil their duties (Morrone et al. 2009: 9).

Just as interpersonal trust is essential for civilized society, so is institutional trust. Citizens' trust in institutions is highly conditional on their observation of others. They trust institutions if they believe others do so as well (Kotzian 2010). ${ }^{6}$ Hence, high institutional trust motivates citizens to support institutions and to comply with them. Conversely, low institutional trust breeds people's distrust in institutions. For example, if the public's trust in police is low because of prevailing high crime rates, people's willingness to comply with the law declines. If citizens' trust in politicians is low because of politicians' breaches of trust, so too would be society's observance of rules and regulations. If corruption is highly prevalent in society, citizens can be more easily tempted to commit corruption themselves. All this indicates that institutional trust, if left unattended, is likely to generate a vicious circle, whereby distrust breeds distrust. This develops a national culture of distrust in institutions, and leads to a dysfunctional society. Once distrust develops as a social norm, it is difficult to change path from distrust to trust, leaving long-lasting adverse effects on society as well as on trust in institutions.

Institutional trust is also important because interpersonal trust is embedded in institutions (Warren 1999: 3). Institutions and in particular the rule of law are expected to provide citizens with safeguards against others' unreliable and unpredictable actions, thereby enhancing interpersonal trust. With increasingly complex society, problems arise from collective actions, which the state institutions are expected to solve. With these collective-action problems adequately addressed by the proper operation of institutions, individuals are encouraged to participate in collective action, which, in turn, raises interpersonal trust. High institutional trust leads citizens to realize that the constitutive rules and norms of institutions are shared by the members of society, enhancing their interpersonal trust (Warren 1999: 7). Hence, institutional trust arising from properly functioning formal institutions is a requisite for interpersonal trust, as supported by an empirical study of Zak and Knack (2001). All these factors indicate that institutional trust and interpersonal trust reinforce each other, creating a virtuous circle between them. By maintaining institutional trust over time as the basis of interpersonal trust, a social culture of institutional and interpersonal trust develops, as evidenced in Singapore after Lee Kuan Yew became Prime Minister in 1959. 
Understanding the close relationship between interpersonal and institutional trust, the task of raising social trust would be done through raising institutional trust by public policies, because interpersonal trust remains quite stable over time and unamenable to public policies (Bjornskov 2012; Algan and Cahuc 2013). Hence, public policies should be employed to raise social trust, largely through changes in institutions and policy implementation. This warrants separate investigation of the two components of social trust. For this study, institutional trust includes trust not only in public institutions, but also in private organizations such as businesses and trade unions.

\subsubsection{Determinants of Institutional Trust}

Citizens' trust or confidence in institutions is based on their evaluation of the performance of institutions as against their expectations. From this, citizens establish their perception of the trustworthiness of the institutions. Since citizens expect that institutions operate competently and ethically, two broad interrelated dimensions or determinants of institutional trust are competence in performing institutional functions assigned by law or social norms, and values (ethics) underlying institutional operations (OECD 2017a). The competence dimension includes efficiency and effectiveness of the institutions, and the value dimension includes integrity (non-corruption) and fairness for the economy and society as a whole.

In practice, institutional trust depends on the performance of institutions as indicated by a number of objective measurements (Kotzian 2010; Warren 1999). In this regard, Kotzian (2010) argues that for all institutions of a nation, objective economic performance (in terms of GDP, inflation, and unemployment) is the most important factor for trust in overall institutions. By this measure, trust in overall institutions would be low in a country with poor economic performance. Equity in income and opportunities is another important indicator of economic performance, and an enhancer of institutional trust (Uslaner and Brown 2005; Rothstein and Uslaner 2005). Finally, one of the most important indicators of institutional performance is the perception of corruption (unethical behaviour), which contributes to lower institutional trust in both developed and developing countries (Chanley et al. 2000; Warren 2006; Blind 2007).

Some country-specific causes also underlie institutional trust, including culture, rules and regulations, and interpersonal trust. Culture plays an important role in establishing and implementing national institutions (Fukuyama 1995: 14; Whiteley 2000; Spolaore and Wacziarg 2013). Formal institutions such as rules and regulations are codifications of morality and ethics, much of which are grounded in culture. ${ }^{7}$ Not only is culture an 
underpinning of formal institutions, but it also affects civic consciousness and obedience of the law. As Tabellini (2010) and Fukuyama (2004: 30) point out, culture also has a strong bearing on the functioning of government agencies and the performance of their personnel. Ultimately, people are responsible for monitoring and controlling the performance of government agencies, and citizens' fulfilment of their responsibility toward these agencies is highly embedded in culture. Success of government agencies requires not only citizens' monitoring and control over them, but also government officials being honest and motivated not by self-interest, but by patriotism and professionalism. These behavioural patterns are rooted in culture. All this indicates that culture should be one of the important determinants of long-term cross-national differences in institutional trust, as argued by Doney et al. (1998).

The rule of law is an essential institution, as it underlies all other institutions of a country, and hence is one of the key determinants of institutional trust. Proper and fair functioning of the rule of law raises citizens' confidence in institutions and in particular public security, thereby raising trust in the institutions (Delhey and Newton 2003). The broken window theory implies that citizens are willing to abide by the laws by observing what others do, or how well the rule of law is being observed in society. Hence, in any country proper functioning of all laws, regardless of whether they are trivial or serious, is critically important to maintaining both the rule of law and high institutional trust. Without proper implementation of the rule of law, other institutions cannot operate properly (Knack and Zak 2003; Blind 2007).

Interpersonal trust is an important factor for institutional trust. Since institutional trust is based on the people's confidence in institutions, which, in turn, is based on the evaluation of institutions in terms of their performance and values, institutional evaluation is a key variable for public trust in institutions. Hence, we may expect institutional trust to be high in a country with high interpersonal trust, as supported by Kotzian (2010), because trusting people evaluate institutions more positively. As explained earlier, 'winners' in society have high interpersonal trust, and for the same reasons they look at institutions more positively, placing higher trust in them. This further supports the two-way causality between interpersonal and institutional trust, as argued above. Morrone et al. (2009) also find from the WVS data a close positive correlation between interpersonal and institutional trust at aggregate national levels. All of these observations and research findings reiterate that the two components of social trust reinforce each other either positively or negatively.

Economic development can have negative effects on institutional trust and in particular trust in government, as observed recently in many advanced countries (Warren 1999: 4; Chanley et al. 2000). As the economy 
develops and people's material well-being improves, people no longer worry for their survival, and they do not need to cling to the authorities. This lowers people's trust particularly in political institutions and government. As education levels improve with economic development, the public may begin to evaluate the institutions and their leaders by more demanding standards, or they may become increasingly sophisticated about the conditions of their trust. Although estimating net effects of economic performance on institutional trust is an empirical issue, it appears that the short-term effect on institutional trust arising from precipitous changes in objective economic performance runs in the same direction, as shown in Korea. ${ }^{8}$

\subsection{MEASUREMENTS OF SOCIAL TRUST}

\subsubsection{Measurements of Interpersonal Trust}

The two components of social trust - interpersonal and institutional trust - are measured differently. The present study takes advantage of measurements of interpersonal trust by the WVS. As mentioned earlier, the percentage of the population of a country who express agreement with the claim 'most people can be trusted' is regarded as the interpersonal trust level of that country. The WVS has carried out six waves of surveys starting from 1981, and as of 2019 the last one was carried out in 2010 for the period 2010-14. Although the WVS asks a set of questions on trust in different groups of people such as neighbours, people you know personally, people you meet for the first time, and so forth, for the present study interpersonal trust is taken as generalized trust or trust in people other than friends and relatives. ${ }^{9}$

Some have argued that the WVS question measures trustworthiness of other people rather than trust per se (Newton 2001). Morrone et al. (2009: 13) have put the concept of trust as 'A trusts B to do X', X being a type of behaviour. The question used by the WVS does not identify who $\mathrm{B}$ is (a friend or stranger, a person known or unknown to A), nor does it specify the type of behaviour (X) A expects of B. To compensate for this shortcoming of the WVS measurement, a few attempts have been made to measure interpersonal trust using different questions, including the question about whether one can expect the return of a dropped wallet, as used by Gallup World Poll (GWP) (Morrone et al. 2009). ${ }^{10}$ Nonetheless, a high level of overlap is found between these questions by the WVS and other organizations. In addition, the trust levels identified by different organizations are highly correlated (Zak and Knack 2001: 306). That is why the WVS measurement of interpersonal trust is used for this book. Based on 
the WVS measurement of interpersonal trust, Chapter 6 explores causes and remedies of low interpersonal trust in Korea.

\subsubsection{Measurements of Institutional Trust}

As defined earlier, institutional trust represents confidence of citizens in institutions. For this study, institutions include not only public institutions (e.g., government, public administration, politicians, bureaucracy, political parties, armed forces, police, judicial system, education system) but also private institutions and organizations (business, labour unions, media, churches). Institutional trust is generally measured through surveys asking individuals to rate their confidence in institutions and organizations. The typical question is, 'How much confidence do you have in the institutions that operate in your country?', although some surveys may ask somewhat differently formulated questions. A number of well-known international organizations measure certain aspects of institutional trust across countries. These organizations include the World Economic Forum (WEF), the International Institute for Management Development (IMD), Transparency International (TI), and the World Bank Group (WBG). The WVS also measures a number of types of institutional trust through surveys. Although the WVS has measured trust in institutions for the longest period of time, the data are available only for multiple year periods (waves), instead of being presented as annual data. This diminishes the consistency of these data and makes it difficult to compare them with the annual measurements by other organizations. The GWP also measures 'confidence in institutions' annually, across countries. GWP's annual cross-country measurements are not readily available, yet relevant data on OECD countries are available in Government at a Glance (OECD 2017b). ${ }^{11}$ Based on numerous measurements of institutional trust by a number of international organizations, Chapter 4 estimates the effects of institutional trust on Korean economic development, and Chapters 7, 8, and 9 explore causes and remedies of low institutional trust in Korea.

\subsection{THE ROLE OF SOCIAL TRUST IN ECONOMIC AND SOCIAL DEVELOPMENT}

\subsubsection{Effects of Social Trust on Social Progress}

Social progress refers to improvements in the sustainable and equitable well-being of a society (Hall et al. 2010). Multiple attempts have been made to measure the progress of society (e.g., Stiglitz et al. 2009; Hall et al. 2010; 
Porter et al. 2017). Social progress is certainly multidimensional, including social, economic, political, cultural, and environmental phenomena. Social cohesion, the focus of this section, has been emphasized by the OECD (2011) as one of the critical elements for sustainable and equitable social development, and is particularly so for Korea (OECD 2013). The OECD $(2011$; 2014) argues that a cohesive society includes three constituent elements: social inclusion, social capital, and social mobility.

Social inclusion refers to the way in which individuals and social groups are included into society through means such as employment, networks, and access to social support programs. In addition, social inclusion requires government policies and systems that make benefits of social support programs (health, education, and housing) equally available to all citizens. Social trust promotes social inclusion, as trusting people have stronger participatory attitudes and behaviours (Knack and Keefer 1997). Such people generally are also more tolerant and empathetic toward others. In this regard, Fukuyama (2010) argues that interpersonal trust, in particular, has positive externalities that help expand the radius of trust. As well, high social trust improves communication among citizens, thereby raising social inclusion.

Social trust is the main component of and contributes directly to social capital, another constituent element of social cohesion. It also has a positive relationship with the other two components of social capital: social norms and networks. Social trust contributes to social mobility, another element of social cohesion, by diminishing people's perception of social classes and discrimination. Also, high trust among family members (or high limited trust) raises investment in education of children and siblings, eventually raising their social mobility. In this regard, Putnam (2000) argues that countries with higher levels of interpersonal trust also have higher levels of not only education, but also of health, public safety, and social and economic equality. These features and consequences of social trust indicate that it certainly contributes to social cohesion and hence to social progress.

The OECD (2014) measures of social cohesion use five indicators including: life satisfaction, tolerance, confidence in institutions, safety and crime, and helping others. Social trust contributes to each of these. ${ }^{12}$ Indeed, there are strong and positive associations between social trust (interpersonal and institutional) and each component of the social cohesion indicators measured by the OECD (2014). Interpersonal trust, in particular, has positive effects on life satisfaction or subjective well-being. This is well supported by a number of empirical studies (Helliwell and Putnam 2004; Helliwell and Wang 2011; Han et al. 2011). Helliwell and Wang (2011) argue for strong linkages between interpersonal trust and two 
major global causes of death - suicides and traffic fatalities - supporting the linkage between social trust and life satisfaction. ${ }^{13}$

Ever more research has been conducted, particularly by positive psychologists, on the role of psychological factors such as trust, optimism, and sociability as determinants of subjective well-being or happiness (Seligman 2002; Lyubomirsky et al. 2005). As discussed above, optimistic people have higher tendencies to trust others, and are happier. Happy and trusting people are more altruistic, more empathetic with others, and more willing to donate to others in need (Seligman 2002: 43). This indicates that social trust contributes to tolerance and helping others, thereby improving social cohesion.

As considered earlier, people with high interpersonal trust have high confidence in legal institutions, and they motivate others to comply with the rule of law, mutually reinforcing interpersonal and institutional trust. Lederman et al. (2002) find that interpersonal trust has a crime-reducing effect, by lowering social conflicts and helping to resolve them in peaceful ways. These findings indicate that interpersonal trust has positive effects on confidence in institutions and safety. Therefore, by having positive associations with the three constituent elements of social cohesion, social trust should have positive relations with social development.

\subsubsection{Effects of Social Trust on Economic Development}

A vast literature has demonstrated a positive relationship between social trust and economic development, and provided empirical studies supporting the relationship (Fukuyama 1995; Knack and Keefer 1997; Whiteley 2000; Zak and Knack 2001; Knack and Zak 2003; Tabellini 2010; Bjornskov 2012). As investigated further in Chapter 4, social trust affects economic development through numerous channels, although they are interrelated. First, social trust facilitates economic activities not only by improving coordination and cooperation among economic agents, but also by reducing the incentives for opportunism. Economic activities are in practice carried out between or among economic agents in a community or organization rather than by one agent alone. To be undertaken efficiently, economic activities require coordination, cooperation, and collaboration among the agents involved.

Second, social trust facilitates economic performance by reducing transaction costs (North 1990). Transaction costs arise through the process of negotiation between economic agents, valuation of goods and services to be exchanged, and enforcement of contracts. A high level of social trust lowers transaction costs because in such a fiduciary and trustful relationship, people generally believe that others will play honestly and by the rules. 
Strong inclination to follow rules and laws also reduces enforcement costs of contracts. ${ }^{14}$ The financial sector (including banking and securities) is particularly trust-sensitive or sensitive to transaction costs, and hence social trust is required for development of the financial sector, which is, in turn, a critical ingredient for economic development. Social trust, by lowering transaction costs, improves access to credit for the poor who can then invest in education and in business undertakings. ${ }^{15}$ Not only do transaction costs affect the economy directly as part of economic costs, they also work as an important determinant of how well markets function. If formal institutions (including protection of private property rights) are appropriately established and implemented, and social trust is high, markets function well with minimum transaction costs. Well-functioning markets lead to a high degree of specialization and division of labour in an economy, which, in turn, leads to a higher level of productivity and economic progress.

Third, social trust contributes to successful implementation of economic policies and the rule of law. A high-trust society increases the supply of honest bureaucrats and politicians. If trust in government and its officials is high, social trust in their policies will also be high. People then undertake their economic activities such as investment and consumption in line with government policies, rendering the policies successful. Similarly, as noted earlier, high social trust raises economic growth through better implementation of the rule of law. A better rule of law, in turn, would help people feel secure in undertaking risky investment and economic activities, as well as lowering transaction costs as mentioned above.

Fourth, social trust facilitates human resource development not only through high investment in education, as noted above, but also through leading recruitment on the basis of meritocracy or educational credentials (Coleman 1988; Bjornskov 2012). If social trust is high, companies hire their staff based on applicants' educational credentials or merits. If, however, social trust is low, companies do so based on trustworthy personal attributes of applicants such as blood, school, or community ties. Hence, in more trusting countries, individuals invest more in education to take advantage of educational credentials.

Fifth, social trust has become increasingly important for economic development under globalization. With intensifying globalization, modes of production and marketing have changed. As a result of fierce competition and at the same time indispensable interdependence among countries, no one firm can undertake all value creating activities involved throughout the value chain. Rather, a common practice for firms is to focus on their core activities with competitive advantages such as R\&D, strategic marketing, and brand names, and to procure the rest of their value creation activities through outsourcing and collaboration throughout the world. Once a 
product is produced through a process of international collaboration, it is then marketed globally also through international collaboration. Thus, to be competitive under globalization, companies have to take advantage of a worldwide division of labour and specialization for both production and marketing. The extent of international specialization and collaboration depends on transaction costs, which, in turn, depend on the level of social trust. In addition, in marketing a product of a country in international markets, the image that foreigners hold of the country where the product is produced is important. If the country's image is highly regarded, the products are likely to be better received in international markets. A country's international image is shaped by many factors, including the perceptions held by foreigners of its culture, the level of social trust among its citizens, and their tolerance and acceptance of foreign cultures.

Sixth, foreign direct investment (FDI) is attracted to countries with high social trust. FDI provides capital, technology, managerial know-how, and marketing skills to host countries. It also helps to raise competitiveness of host countries through enhanced networking, competition, and improved institutions and transparency. Thus, FDI is critically important to economic development of host countries. A number of Asian countries have achieved rapid export-led industrialization and high economic growth as a result of incoming FDI (Tiwari and Mutascu 2011; Jun 2015). To attract FDI, host countries have been eager to liberalize FDI regimes and streamline the FDI process more or less to the same extent. Social trust of host countries has therefore emerged as an increasingly important variable in attracting FDI, due to the difficulties in emulating social trust among countries. Foreigners will be reluctant to undertake FDI, including international joint ventures, in a country with low social trust.

Seventh, social trust affects creativity and innovation of organizations, through its effects on not only education and division of labour, as discussed above, but also on business cooperation and collaboration. In the contemporary period, not just advanced countries' economies but also many emerging economies, including the Korean economy, are gearing toward a knowledge-based structure that requires a constant flow of innovation for survival. Creativity and innovation are at work in creating something new, more valuable, and convenient for consumers, usually by connecting existing technologies, skills, ideas, and designs to meet consumers' predilections. ${ }^{16}$ Hence, creativity and innovation require a wide variety of social relationships and collaboration among people domestic and international - with these ingredients of creativity. In this context, Chesbrough (2003) introduced the concept of 'open innovation', which refers to a wide scope of exploration and integration of innovative ingredients internally and externally. For success, open innovation requires 
trust, cooperation, and collaboration among possible partners. It is well known that people involved in creative activities require autonomy for their creativity. However, autonomy is usually not allowed in employment situations where trust levels are low (Akcomak and ter Weel 2009).

Eighth, social trust is further required for high-tech R\&D and for evolving digital economies. Fukuyama (2010) pointed out that much high-tech R\&D depends on informal exchanges of intellectual property rights because formal exchanges entail excessive transaction costs that slow down the speed of interchange. As economic activities are increasingly undertaken digitally, electronic economic transactions such as e-commerce through the Internet become more trust-sensitive, because economic agents involved in digital commerce - partners, suppliers, and customers - do not liaise with each other in person. This renders social trust more important for digital economic transactions.

Ninth, high social trust helps to raise the productivity of firms by enabling them to highly decentralize their organizations (Fukuyama 1995; Bloom et al. 2012). One way that firms decentralize their organization is to assign specific tasks to teams of workers. In the 1930s it was found that organizing workers into small groups with substantial group autonomy had a large, positive effect on company productivity (Fukuyama 1995: 203). A group or team comprises a number of people with the expertise required for the team's designated task. However, trust among the team members is vital for successful teamwork. In a country with low social trust, a high level of trust at the company level cannot be expected. Without high trust, companies are reluctant to provide autonomy to a team because the team might abuse its autonomy, and the team members cannot be expected to cooperate and collaborate among themselves even for the goals they share with each other and with the company.

In summary, all the arguments, as illustrated above, for the positive effects of social trust on economic development suggest strongly that countries with higher levels of social trust among their citizens will have a better economic performance, as revealed by higher levels of economic growth. The empirical studies discussed below offer useful affirmation and illustration of this principle.

Empirical studies that have sought to estimate quantitatively the relationship between social trust and economic growth include those by Knack and Keefer (1997), Whiteley (2000), Zak and Knack (2001), Knack and Zak (2003), Tabellini (2010), Bjornskov (2012), and Algan and Cahuc (2013). A seminal empirical study by Knack and Keefer (1997) showed a 10 -percentage-point rise in interpersonal trust is associated with an increase in economic growth of four-fifths of a percentage point. Zak and Knack (2001) estimated a 15-percentage-point increase in interpersonal trust in a 
country raises per capita output growth by one percentage point for every year thereafter while conditions prevail. ${ }^{17}$ Whiteley (2000) argued that interpersonal trust (or social capital) has an impact on economic growth at least as strong as that of human capital or education. ${ }^{18}$ Consistent with these studies relating high trust in society with high growth in economy, Foa (2011) estimated the quantitative relationship between social cohesion, which is affected by social trust, as discussed above, and economic development. For Foa's estimated index of social cohesion, Korea scored 6.07, ranking 25 th out of 155 countries. His estimates showed that a two-point increase in the index, which is slightly larger than the gap between Korea and Switzerland (7.93), is sufficient to produce a 28-percentage-point difference in cumulative economic growth over the period (1991-2008). ${ }^{19}$

These empirical studies, although valuable in some ways, appear to be limited in measuring the effects of social trust on economic development in Korea. Available quantitative estimates have been calculated through linking interpersonal trust levels measured by the WVS and economic growth rates. They are typically in the form of cross-country estimates, not estimates over time. Hence, the effects of changes in social trust over time on growth of an economy are not estimated. Furthermore, insofar as institutional trust is not reflected fully in interpersonal trust, these results show only part of the effects of social trust on economic development.

\subsection{HOW TO RAISE SOCIAL TRUST}

This chapter has examined the concepts and determinants of social trust and discussed the importance of social trust for a country's social and economic development. The most important and challenging concern, then, is how to raise social trust within a country, particularly through public policy. The following discussion of policy measures turns first to raising interpersonal trust, then to raising institutional trust. It then considers public strategies oriented to their shared determining factors, to raise both constituent elements of social trust simultaneously. Drawing from theoretical and other discussion in this chapter, ways to raise interpersonal and institutional trust specifically in Korea are explored systematically later in this book, in Chapter 6 and Chapters 7-9 respectively.

\subsubsection{How to Raise Interpersonal Trust}

For building interpersonal trust, the morality-based theory emphasizes childhood education from parents at home and from schools, not only on moral norms and values but also on observance of the rule of law (Helliwell 
and Putnam 2004). The quantity of education surely matters, but so too do teaching methods, which of themselves are critical in raising interpersonal trust. Algan and Cahuc (2013) argue that of the two typical teaching practices, 'vertical teacher lectures' and 'horizontal student work in groups', the former has a rather negative effect on fostering interpersonal trust, while the latter has a substantial positive impact particularly on students' interpersonal trust. Parents and school authorities should be role models of morality because children observe, emulate, and learn from adult behaviour. Education on morality should not be limited to school education, but should be extended into society, companies, and professional groups to inform and encourage ethical behaviour. The experience-based theory of interpersonal trust suggests that to build interpersonal trust in a country, social and economic policies should be implemented to improve income equality as well as economic development, and by extension to minimize social stratification and discrimination.

The society-based theory of interpersonal trust indicates that strongly knit groups with a narrow radius of limited trust produce negative externalities that render adverse effects on interpersonal trust. In Korea, for instance, many types of rituals such as wedding and funeral services are conducted among group members in lavish ways to impress through display of wealth and to consolidate limited trust. Politicians take advantage of regionalism for their election. These group-based activities generate jealousy, conflict, and anger in society, and reduce interpersonal trust. Hence, social campaigns should be promoted with government support, which would discourage overt and lavish group-based activities.

The society-based theory also suggests public policies that improve equity in income and social status as well as overall economic development, to raise interpersonal trust. Knack and Keefer (1997) argue from their empirical study that reducing social polarization and income disparities is a key way to raise social trust. An extensive empirical study by Delhey and Newton (2003) shows that social conflicts and public safety are two key variables for interpersonal trust. In this regard, all areas of public policy should be rooted in understandings of conflict prevention and ensuring public safety, alongside high-quality legal institutions that operate fairly for all. In recent years in particular, inequity in income and wealth has been emphasized as a critical source of many types of social problems and social distrust as well as low economic performance. Hence, inequity in Korea is explored in various contexts in chapters throughout this book. 


\subsubsection{How to Raise Institutional Trust}

As interpersonal and institutional trust are closely related and mutually reinforcing, public policy to raise interpersonal trust can be applied directly or indirectly to also raising institutional trust. Institutional trust is generated through public confidence in institutions, born of both the ethical and effective performance of these institutions and the trustworthiness of their personnel. To enhance institutional trust, a nation's public policies should undertake a few specific tasks: (i) fair and effective implementation of legal institutions; (ii) enhancement of social justice; (iii) economic development with employment; and (iv) enhancement of equity in income and economic opportunities. It should be emphasized that a fair and effective implementation of the legal system is one of the key factors for institutional trust. The incidence of crime, fraud, and scams, which indicate ineffective performance of the legal system, decreases institutional trust. But above all, corruption and malfeasance of government officials, business leaders, and union executives appear to be the most important factors. Public perception of corruption lowers citizens' trust in government and in fair and effective implementation of the legal system, leading some citizens to lower their observance of rules and regulations and thus breeding more corruption. In this light it is clear that proper enforcement of laws against illegal activities committed by executives of companies and trade unions is a prerequisite for institutional trust in private organizations.

Social injustice, which can create or deepen social conflict and distrust, may arise from various sources. Fairness of both the legal system and its implementation are vital for social justice. Public perception of injustice created by unfair law enforcement - for example, favouring politicians, high-level civil servants, and business and union executives, as evident in the case of Korea - may lead to public distrust in the legal system and other institutions. Unfair practices in the labour market on the basis of gender, racial background, or other irrelevant personal qualities are serious sources of injustice in society, which warrant strong public policy to end them. Freedom of the press is vital for proper functioning of public institutions and thus for social justice, since the press plays a crucial role in monitoring and controlling public institutions. In addition, to enhance social justice, socially inclusive policies are required, making available social programs and their benefits to all targeted citizens.

Economic policy should be implemented in such a way as to promote economic development and employment because they are indicators of confidence of overall public institutions. Equity in income and economic opportunities is another important indicator for proper operations of public institutions. Social policies can also play a vital role in this regard 
since, through social policies, income and other social benefits can be transferred to those in need, helping to create the equity across income and economic opportunities.

\subsubsection{How to Raise Social Trust Through Both Components}

The two components of social trust - interpersonal trust and institutional trust - are closely related and have a number of determining factors in common, so a set of public strategies that is mindful of these shared determining factors is most useful for simultaneously raising the two constituent elements of social trust. As the discussion above suggests, both the determinants and the ways of promoting the two components of social trust overlap considerably. Bearing in mind this overlap, four particularly significant measures for raising social trust simultaneously through interpersonal and institutional trust are proposed and reiterated here. The first measure is provision of education of ethics and socialization to children at home and at school so that they are better placed to abide by social norms and values as well as by the rule of law. Education in morality should also be extended across society to elevate the ethical and legal standards of society as a whole.

Second, to establish a stable trend in the development of social trust over time, public policies should seek to raise interpersonal and institutional trust concomitantly through improvements to institutions in the short-run. In devising such improvements, it needs to be understood that in all societies social trust depends upon a foundation of equality and justice under the law. Legal egalitarianism, or belief in the equality of all before the law, is a critical underpinning of equality and justice in practice. Hence, the rule of law should be implemented fairly, properly, and consistently, as, indeed, prescribed within the law.

Third, an aspect of equality and justice that profoundly affects social trust is the economic dimension, where inequality and injustice can generate social conflict and lower social trust. Economic policies should be designed to promote not only economic development, but also equality in income, wealth, and opportunities. As investigated in Chapter 5, evidence is mounting that growth in income inequality impedes both economic productivity and economic growth. This invalidates the traditional argument for efficiency-equity trade-offs, and supports the notion that countries need to include specific and aggressive redistributive policies as part of their national economic development policy. A global trend in recent years has seen continuous growth in the gap in income and wealth between the rich and poor within countries. However, to remedy this divisive situation, any single country will be reluctant to implement its own redistributive 
policy unless other countries do the same, because globalization has intensified competition among countries. Designing and implementing such redistributive policies will therefore require coordination among countries, or at least among countries within institutionalized groups such as the OECD.

Fourth, the measures identified here to raise interpersonal and institutional trust highlight the need for a coordinated, multidimensional approach to public policymaking for social and economic development. Public policies concerning specific areas of social trust are explored further in subsequent chapters of this book.

\subsection{CONCLUSION}

This chapter has explained the seriousness of low social trust in Korea. It has explored conceptually the importance of social trust for economic and social development as well as for human well-being. In this regard, the main purpose of this chapter is to develop a working definition of social trust and a conceptual framework, both of which underlie this book throughout. From this, it is attempted to propose some specific public policies to raise social trust.

This chapter has discussed interpersonal and institutional trust separately as the two constitutive components of social trust. Acknowledging their mutually complementary relationships, it is argued that social trust goes beyond interpersonal trust simply because society consists of not only individuals but also other social components such as social groups, institutions, and organizations. It is neither practical nor feasible to conflate institutional trust with interpersonal trust because their concepts and determinants are different from each other. They are also identified and measured separately by a number of worldwide organizations. In particular, Korea's interpersonal and institutional trust are both markedly lower than those of neighbouring countries as well as advanced countries. Furthermore, by comparison with these other countries, Korea's institutional trust is relatively lower than interpersonal trust. The exploratory framework of this book therefore examines the two constituents of social trust separately, which is consistent with the institutional approach adopted by this book on issues of social and economic development.

Social trust and economic development are closely interrelated. This chapter has discussed how social trust directly and critically affects economic development, and how economic development, including economic growth, employment, and equity, influences social trust. This implies that low social trust in Korea is to a considerable extent a consequence of 
maintaining the focus of economic policy narrowly on economic growth for too long, and that low and still declining social trust has now become an impediment to Korea's economic growth as well as to social progress.

In light of the general determinants of interpersonal and institutional trust investigated in this chapter, some public policies to raise social trust have been proposed. These policies are devised on the principle that social trust is self-reinforcing; rising social trust induces people to trust each other further. Consistently, where social trust has been at a low level for an extended period, it is difficult to build or rebuild trust in society. Therefore, a key point here is that level of social trust should continuously be a concern for policymakers, especially since social trust operates in a virtuous - or vicious - circle with economic development. Maintaining social trust not just for its social benefits but also for its economic benefits needs to be a significant underpinning of national policy, as the following chapters exploring the Korean example make clear.

\section{NOTES}

1. Over the six waves of the WVS, Korea's scores have changed from 36.0 by Wave 1 (1981-84), to 33.6 by Wave 2 (1989-93), to 30.3 by Wave 3 (1994-98), to 27.3 by Wave 4 (1999-2004), to 28.0 by Wave 5 (2005-09), and to 26.5 by Wave $6(2010-14)$, with an average score of 30.3 over the six waves (WVS 2015).

2. Attempts have been made in the literature to identify the direction of the causality between the two components of social trust. However, conceptually, the two types are mutually influencing and complementary. For this, see Morrone et al. (2009), Kotzian (2010).

3. The society-based theory differs from the experience-based individual theory, in that for the former, experiencing takes place within society alongside social variables, while for the latter, experiencing takes place with other individuals.

4. In the case of Korea, country-fixed characteristics explain 48 percent of the difference between Korea's generalized interpersonal trust level and the level of the world's highest ranked, Norway, with its trust level of 68.1, as measured by the WVS, 1981-2008 (Algan and Cahuc 2013). This means that for an average Korean person who lived during that period in Norway rather than in Korea, his/her trust level would be 49.2, instead of 31.7, or his/her trust level would increase by 55.2 percent.

5. Germany is an exceptional case, with loss of social trust soon after WWII, but remarkable recovery from 9 percent in 1948 to 45 percent in 1993 (Newton 2013).

6. This is referred to as 'conditional trust', which is conceptually equivalent to 'conditional cooperation'. For the former, see Kotzian (2010); for the latter, see Gachter (2007).

7. In this respect, Obama (2006) said, 'Our law is by definition a codification of morality'.

8. Roth (2006) finds that economic growth is negatively related to changes in interpersonal trust in developed countries, while it is positively related in developing countries.

9. A number of other measurements of interpersonal trust are available. See Morrone et al. (2009).

10. The so-called 'dropped wallet question' works as follows. Suppose that somewhere in your city you lost your wallet with, say, $\$ 100.00$ and your identification. Do you think your wallet will be returned to you if someone finds it?

11. Although there are a few other measurements of institutional trust, such as those by 
the European Union's Eurobarometer and by the Edelman Trust barometer, they are not so useful for the present study. Measurements of institutional trust by these two organizations cannot be easily compared with each other, since they use different survey questions, institutions, expression and category of trust levels, time periods, and frequency of survey (Morrone et al. 2009).

12. Hall et al. (2010) include a large number of dimensions of social progress, including ecosystem, human well-being, economy, and governance. As to social dimensions, however, there are large overlaps between the components of social cohesion by OECD (2014) and those by Hall et al. (2010). Although OECD (2016) uses a set of indicators of social cohesion slightly different from those used in OECD (2014), these indicators are in essence more or less the same.

13. As explored in Chapter 6, Korea has a low level of social trust and the highest rates of suicide and of road fatalities among OECD countries (KOSIS 2018), supporting the findings of Helliwell and Wang (2011).

14. North (1993) cites an empirical study that found 45 percent of US GNP was devoted to the transaction sector in 1970. Studies on the effects of social capital (or social trust) on transaction costs include Putnam (1995) and Dyer and Chu (2002). Wang (2003) surveys the studies that have measured transaction costs.

15. For empirical support for the relationship between social trust and the financial sector, a number of sources are cited in Algan and Cahuc (2013).

16. These observations on creativity were made by Steve Jobs, entrepreneur, business magnate, and co-founder of Apple Inc., who was regarded as the most creative person in the US for several years in the late 20th century.

17. As Bjornskov (2012) observed, the results of a number of the empirical studies cited here are quite consistent with each other. The implication of these empirical results for Korea is quite alarming. Interpersonal trust decreased in Korea from 36 percent with the 1981-84 wave of the WVS to 26.5 percent with the 2010-14 wave. This implies that, according to the estimate by Knack and Keefer (1997), the decrease in interpersonal trust by 9.5 percentage points over the period 1981-2010 would have lowered the economic growth rate by 0.76 percentage points. Korea's actual annual economic growth rate over the period 1981-2010 was 7.1 percent. If the interpersonal trust level remained unchanged at the 1981 level, the average growth rate over the period would be 7.86 percent.

18. Knack and Keefer (1997) show that the impact of interpersonal trust on economic growth is slightly less than the impact of primary education. Their research shows that a one-standard-deviation change in trust (14 percentage points) is associated with a change in growth of 0.56 of a standard deviation, as compared to 0.64 for primary education.

19. It is interesting to note that the empirical study by Algan and Cahuc (2013) shows that limited trust in society does not contribute to economic growth.

\section{REFERENCES}

Akcomak, S. and B. ter Weel (2009), 'Social capital, innovation and growth: evidence from Europe', European Economic Review, 53(5), 544-67.

Alesina, A. and E. La Ferrara (2002), 'Who trusts others?', Journal of Public Policy, 85(2), 207-34.

Algan, Y. and P. Cahuc (2013), 'Trust and growth', Annual Review of Economics, 5(1), 521-49.

Arrow, Kenneth (1999), 'Observations on social capital', in P. Dasgupta and I. Serageldin (eds), Social Capital: A Multifaceted Perspective, Washington, DC: World Bank, pp. 3-5. 
Berggren, N. and C. Bjornskov (2009), 'Is the importance of religion in daily life related to social trust? Cross-country and cross-state comparisons', Ratio Working Paper 143, the Ratio Institute.

Bjornskov, C. (2007), 'Determinants of generalised trust: a cross-country comparison', Public Choice, 130(1-2), 1-21.

Bjornskov, C. (2012), 'How does social trust affect economic growth?', Southern Economic Journal, 78(4), 1346-68.

Blind, P.K. (2007), 'Building trust in government in the twenty-first century: review of literature and emerging issues', paper presented at the 7th Global Forum on Reinventing Government, Building Trust in Government, June 2007, Vienna.

Bloom, N., R. Sadun and J.V. Reenen (2012), 'The organization of firms across countries', Quarterly Journal of Economics, 127(4), 1663-705.

Chanley, Virginia A., T.J. Rudolph and W.M. Rahn (2000), 'The origin and consequences of public trust in government: a times series analysis', Public Opinion Quarterly, 64(3), 239-57.

Chesbrough, H.W. (2003), Open Innovation, Boston: Harvard Business School Press.

Coleman, J. (1988), 'Social capital in the creation of human capital', American Journal of Sociology, 94(4), S95-S120.

Coleman, J. (1990), Foundation of Social Theory, Cambridge, MA: Harvard University Press.

DeBruine, Lisa (2002), 'Facial resemblance enhances trust', Proceedings of the Royal Society of London, 269(1498), 1307-12.

DeConick, J.B. (2010), 'The effect of organizational justice, perceived organizational support, and perceived supervisor support on marketing employees' level of trust', Journal of Business Research, 63(12), 1349-55.

Delhey, J. and K. Newton (2003), 'Who trusts? The origin of social trust in seven societies', European Societies, 5(2), 93-137.

Delhey, J. and K. Newton (2005), 'Predicting cross-national levels of social trust: global pattern or Nordic exceptionalism', European Sociological Review, 21(4), 311-27.

DeSteno, D. and P. Valdesolo (2011), Out of Character: Surprising Truths about the Liar, Cheat, Sinner (and Saint) Lurking in All of Us, NY: Random House LLC.

Doney, P.M., J. Cannon and M.R. Mullen (1998), 'Understanding the influence of national culture on the development of trust', Academy of Management Review, 23(3), 601-20.

Dong A Ilbo, The (2014), 'Distrust trap even by the future generation: only $12 \%$ of the middle and high school students said that Korean society is trustworthy', The Dong A Ilbo, 2 September.

Dyer, Jeffrey H. and W. Chu (2002), 'The role of trustworthiness in reducing transaction costs and improving performance: empirical evidence from the United States, Japan, and Korea', mimeograph.

Ermisch, J. and D. Gambetta (2010), 'Do strong family ties inhibit trust?', Journal of Economic Behavior and Organizations, 75(3), 365-76.

Ermisch, J., D. Gambetta, H. Laurie, T. Siedler and S.S.N. Uhrig (2009), 'Measuring people's trust', Journal of Royal Statistical Society: Series A, 172(4), 749-69.

Foa, Roberto (2011), 'The economic rationale for social cohesion: the cross-country evidence', paper presented at International Conference on Social Cohesion and Development, OECD Development Centre, Paris, 20-21 January. 
Fukuyama, F. (1995), Trust: The Social Virtues and the Creation of Prosperity, New York: Simon \& Schuster.

Fukuyama, F. (2004), State-Building: Governance and World Order in the 21st Century, Ithaca, New York: Cornell University Press.

Fukuyama, F. (2010), 'Social capital, civil society and development', Third World Quarterly, 22(1), 7-22.

Gachter, Simon (2007), 'Conditional cooperation: behavioral regularities from the lab and the field and their policy implications', in B.S. Frey and A. Stutzer (eds), Economics and Psychology: A Promising New Cross-Disciplinary Field, Cambridge, MA, USA and London UK: The MIT Press, pp. 19-50.

Hall, Joh, E. Giovannini, A. Morrone and G. Ranuzzi (2010), 'A framework to measure the progress of societies', OECD Working Paper No. 34.

Han, Sehee, H. Kim and H.S. Lee (2011), 'Social capital and its association with health and well-being: an individual level of analysis in Seoul, South Korea', Korea Journal, 51(4), 132-61.

Helliwell, J.F. and R.D. Putnam (2004), 'The social context of well-being', Philosophical Transactions of the Royal Society B, 359(1449), 1435-46.

Helliwell, J.F. and S. Wang (2011), 'Trust and well-being', International Journal of Wellbeing, 1(1), 42-78. Available at: www.internationaljournalofwellbeing.org/ index.php/ijow/article/view/3/85.

Hofstede, G. (1991), Cultures and Organizations: Software of the Mind, London: McGraw-Hill.

Jun, Sangjoon (2015), 'The nexus between FDI and growth in the SAARC member countries', Journal of East Asian Economic Integration, 19(1), 39-69.

Katz, H.A. and J.B. Rotter (1969), 'Interpersonal trust scores of college students and their parents', Child Development, 40(2), 657-61.

Kelleher, C.A. and J. Wolak (2007), 'Explaining public confidence in the branches of state government', Political Research Quarterly, 60(4), 707-21.

Knack, S. and P. Keefer (1997), 'Does social capital have a payoff? A cross-country investigation', The Quarterly Journal of Economics, 112(4), 1251-88.

Knack, S. and P.J. Zak (2003), 'Building trust: public policy, interpersonal trust, and economic development', Supreme Court Economic Review, 10, 91-107.

KOSIS (2018), Social Indicators in Korea 2017, Daejeon: Statistics Korea.

Kotzian, Peter (2010), 'Conditional trust: the role of individual and system-level features for trust and confidence in institutions', Zeitschrift fur Vergleichende Politikwissenshaft, 5(1), 25-49.

Larzelere, R.J. and T.L. Huston (1980), 'The dyadic trust scale: toward understanding interpersonal trust in close relationships', Journal of Marriage and the Family, 42(3), 595-604.

Le, Stephen H.T. (2013), 'Societal trust and geography', Cross-Cultural Research, 47(4), 388-414.

Lederman, D., N. Loayza and A.M. Menendez (2002), 'Violent crime: does social capital matter?', Economic Development and Cultural Change, 50(3), 509-39.

Lee, Dong-won and G.Y. Jeong (2009), The Third Capital, Seoul: SERI (Samsung Economic Research Institute).

Lyubomirsky, S., K.M. Sheldon and D. Schkade (2005), 'Pursuing happiness: the architecture of sustainable change', Review of General Psychology, 9(2), 111-31.

Morrone, A., N. Tontoranelli and G. Ranuzzi (2009), 'How good is trust? Measuring trust and its role for the progress of societies', OECD Statistics Working Paper 2009/03, OECD. 
Newton, K. (2001), 'Trust, social capital, civil society, and democracy', International Political Science Review, 22(2), 201-14.

Newton, K. (2006), 'Political support: social capital, civil society and political and economic performance', Political Studies, 54(4), 846-64.

Newton, K. (2013), 'Social and political trust', Norwegian Social Science Data Services, retrieved from the website of European Social Survey Education Net. Available at: http://essedunet.nsd.uib.no/cms/topics/2/.

North, D.C. (1990), Institutions, Institutional Change and Economic Performance, Cambridge, UK: Cambridge University Press.

North, D.C. (1993), 'Economic performance through time', Douglass C. North Nobel Prize lecture.

Obama, B. (2006), Audacity of Hope, New York: Crown/Three Rivers Publishing.

OECD (2011), Perspectives on Global Development 2012: Social Cohesion in a Shifting World, Paris: OECD.

OECD (2013), Strengthening Social Cohesion in Korea, Paris: OECD.

OECD (2014), Society at a Glance, Paris: OECD.

OECD (2016), Society at a Glance, Paris: OECD.

OECD (2017a), Trust and Public Policy: How Better Governance can Help Rebuild Public Trust, Paris: OECD.

OECD (2017b), Government at a Glance, Paris: OECD.

Offe, Claus (1999), 'How can we trust our fellow citizens?', in Mark E. Warren (ed.), Democracy and Trust, Cambridge, UK: Cambridge University Press, pp. 42-87.

Paldam, M. and G.T. Svendsen (2000), 'An essay on social capital: looking for the fire behind the smoke', European Journal of Political Economy, 16(2), 339-66.

Porter, M.E., S. Stern and M. Green (2017), Social Progress Index, Washington, DC: Social Progress Imperative.

Putnam, R.D. (1993), Making Democracy Work: Civic Traditions in Modern Italy, NJ, USA: Princeton University Press.

Putnam, R.D. (1995), 'Bowling alone: America's declining social capital', Journal of Democracy, 6(1), 65-78.

Putnam, R.D. (2000), Bowling Alone: The Collapse and Revival of American Community, New York: Simon \& Schuster.

Reader's Digest (2015), 'Art of living: one is the loveliest number', Reader's Digest, October 2015, 29-31.

Roth, F. (2006), 'Trust and economic growth: conflicting results between crosssectional and panel analysis', Ratio Working Papers 102, the Ratio Institute.

Rothstein, B. and D. Stolle (2008), 'The state and social capital: an institutional theory of generalized trust', Comparative Politics, 40(4), 441-59.

Rothstein, Bo and E.M. Uslaner (2005), 'All for all: equality, corruption, and social trust', World Politics, 58(1), 41-72.

Seligman, M.E.P. (2002), Authentic Happiness, Australia: Random House.

Spolaore, E. and R. Wacziarg (2013), 'How deep are the roots of economic development?', Journal of Economic Literature, 51(2), 325-69.

Stiglitz, J., A. Sen and J.-P. Fitoussi (2009), 'Report by the Commission on the measurement of economic performance and social progress'. Available at: www. stiglitz-sen-fitoussi.fr/documents/rapport_anglais.pdf.

Tabellini, G. (2008), 'The scope of cooperation: values and incentives', Quarterly Journal of Economics, 123(3), 905-50.

Tabellini, G. (2010), 'Culture and institutions: economic development in the regions of Europe', Journal of European Economic Association, 8(4), 677-716. 
Tiwari, A.K. and M. Mutascu (2011), 'Economic growth and FDI in Asia: a paneldate approach', Economic Analysis \& Policy, 41(2), 173-87.

Uslaner, Eric M. (2008), 'The foundations of trust: macro and micro', Cambridge Journal of Economics, 32(2), 289-94.

Uslaner, Eric M. and M. Brown (2005), 'Inequality, trust, and civic engagement', American Politics Research, 33(6), 868-94.

Wang, Ning (2003), 'Measuring transaction costs: an incomplete survey', Ronald Coast Institute, Working Paper 2.

Warren, Mark E. (1999), 'Introduction', in Mark E. Warren (ed.), Democracy and Trust, Cambridge, UK: Cambridge University Press, pp. 1-21.

Whiteley, P.F. (2000), 'Economic growth and social capital', Political Studies, 48(3), 443-66.

WVS (World Values Survey) (2015), WVS 1981-2014 Longitudinal File, UK: World Values Survey.

Zak, P.J. and S. Knack (2001), 'Trust and growth', Economic Journal, 111(470), 295-321. 